\title{
PERFORMANSI GENSET BENSIN 2000 W YANG DIMODIFIKASI MENJADI GENSET BERBAHAN BAKAR BIOGAS
}

\author{
Maridjo, Tina Mulya Gantina dan M.Taufiq Samudra \\ Jurusan Teknik Konversi Energi - Politeknik Negeri Bandung \\ Jl. Gegerkalong Hilir, Ds Ciwaruga - Bandung 40551 \\ Email : mmaridjo@gmail.com
}

\begin{abstract}
Biogas is one of energy alternative sources, produced from organic materials degradation in anaerob condition that has economically and availability advantages. This research had been conducted to convert biogas to electric power or as known as bio-electric which using a modified carburetor of gasoline genset converter. Biogas was produced from cow's manure fermentation, located at Giri Mekar, Kecamatan Cilengkrang, Kabupaten Bandung. Methane $\left(\mathrm{CH}_{4}\right)$ concentration was $40 \%$ from the biogas with potential energy $43,5 \mathrm{MJ} / \mathrm{kg}$. The result showed that genset with biogas as fuel could reach $989 \mathrm{~W}$ output of capacity with $2,95 \times 10^{-4} \mathrm{~kg} / \mathrm{s}$ of fuel consumption and $11,9 \%$ of maximum efficiency. Compare to gasoline as a fuel, the result showed $1219 \mathrm{~W}$ output of capacity with $1,63 \times 10^{-4} \mathrm{~kg} / \mathrm{s}$ of fuel consumption and $17,2 \%$ of maximum. Therefore, to have same output of capacity, a genset with biogas as fuel is more consuming than genset with gasoline as fuel.
\end{abstract}

\section{PENDAHULUAN}

Kebutuhan pasokan listrik meningkat tajam sehubungan dengan laju pertambahan penduduk dan perkembangan aktivitas ekonomi. Kebutuhan pasokan listrik untuk penerangan rumah tangga di daerah pedesaan, sebagian besar dipenuhi dari bahan bakar berupa kayu, sedangkan penggunaan minyak bumi dan gas alam belum terjangkau secara ekonomi oleh masyarakat kalangan bawah. Dampak dari hal tersebut adalah, terjadinya penebangan pohon secara tak terkendali yang berakibat pada penurunan kemampuan bumi dalam menyerap gas $\mathrm{CO}_{2}$. Terganggunya keseimbangan alam ini telah menyebabkan terjadinya efek gas rumah kaca, sehingga memicu terjadinya pemanasan global. Pencarian sumber energi alternatif yang murah dan mudah akan membantu masyarakat dalam meringankan beban masyarakat dan juga meminimalisir terjadinya kerusakan hutan dan pencemaran lingkungan.

Salah satu sumber energi alternatif yang murah dan mudah disediakan di lingkungan pedesaan adalah biogas yang dihasilkan dari penguraian biomassa secara anaerob. Energi biogas dapat diperoleh dari air limbah rumah tangga seperti kotoran cair dari peternakan kerbau, sapi, babi. Biogas merupakan campuran gas metana dan karbon dioksida sehingga dapat dibakar seperti layaknya gas elpiji untuk
Keywords : performance, genset 2000 w, biogas

memasak, dan penerangan. Biasanya biogas dimanfaatkan untuk proses pembakaran. Namun, Lembaga Ilmu Pengetahuan Indonesia (LIPI) Bandung telah mengembangkan biogas yang dikonversi ke energi listrik yang bernama bioelektrik dengan konverter berupa genset bensin yang telah dimodifikasi. Genset biogas adalah generator yang menghasilkan energi listrik berbahan bakar biogas. Genset biogas merupakan suatu inovasi teknologi yang akan berdampak luas, konservasi lingkungan dan yang terpenting adalah kemampuannya dalam mensubstitusi sumber energi tak terbarukan, dimana saat ini cadangan minyak bumi dan gas alam yang semakin menipis. Bahan baku energi yang dipakai adalah kotoran sapi. Hal ini dikarenakan besarnya potensi sumber energi terbarukan di Kabupaten Bandung yang berasal dari kotoran ternak sapi. Salah satu daerah yang memiliki potensi terbesar berada di Desa Giri Mekar, Kecamatan Cilengkrang, Kabupaten Bandung. Di pedesaan yang sebagian besar penduduknya peternak ini, memiliki 2.000 ekor sapi yang menghasilkan 300 ton kotoran tiap harinya.

Bioelektrik berbasis kotoran sapi ini sangat relevan karena berdasarkan data 2007, sampai saat ini masih ada 1.500 kepala keluarga dari 11.000 kepala keluarga yang belum bisa menikmati listrik di Kecamatan Cilengkrang tersebut. Dengan memanfaatkan bioelektrik, 
masyarakat bisa mendapatkan energi 700 watt dari tiga ekor sapi. Selain itu, mereka bisa menghemat penggunaan bahan bakar minyak atau gas untuk memasak dan solar sampai 70 persen. Di mana dari setiap kepala keluarga yang memiliki tiga ekor sapi per harinya akan dihasilkan $45 \mathrm{~kg}$ kotoran. Selanjutnya, kotoran itu dicampur air dengan perbandingan 1:2.

Sehubungan dengan hal tersebut, maka perlu dilakukan upaya yang sistematis untuk menerapkan energi alternatif yang layak bagi masyarakat tersebut. Dengan latar belakang yang telah dipaparkan di atas, maka penulis membuat penelitian dengan judul "Performansi genset bensin 2000 watt yang dimodifikasi menjadi genset berbahan bakar Biogas", untuk menguji dan menganalisis sejauh mana potensi yang dimiliki oleh biogas yang dikonversi menjadi bioelektrik dengan menggunakan genset berbahan bakar bensin tersebut. Dengan didukung ketersedian bahan baku di lingkungan sekitar peternakan, yang pada umumnya bersifat kontinyu sehingga sangat cocok diterapkan teknologi reaktor dengan tipe continuous. Modifikasi genset berbahan bakar biogas ini diharapkan dapat menaikkan performansi dari genset biogas yang lain dan terjangkau untuk dipergunakan oleh masyarakat.

\section{METODOLOGI ·}

Dalam melakukan penelitian ini metodologi ini metodologi yang dilakukan adalah metode pengujian, tahapan penelitian meliputi :

1. Mengkaji karakteristik biogas, Untuk mengetahui komposisi dari biogas yang bertujuan untuk mengetahui persen metan sebagai bahan bakar genset biogas dan penentuan LHV biogas.

2. Modifikasi genset dilakukan pada bagian karburator dan ruang bakar serta pelepasan ruang pelampung pada genset.

3. Pengujian performansi genset ALGEN berbahan bakar bensin dengan kapasitas maksimal 2000 Watt yang telah dimodifikasi menjadi menggunakan bahan bakar biogas.

Pelaksanaan pengujian dibagi menjadi 2 pengujian yaitu:
1. Pengujian genset dengan menggunakan bahan bakar bensin

2. Pengujian genset dengan menggunakan . bahan bakar biogas.

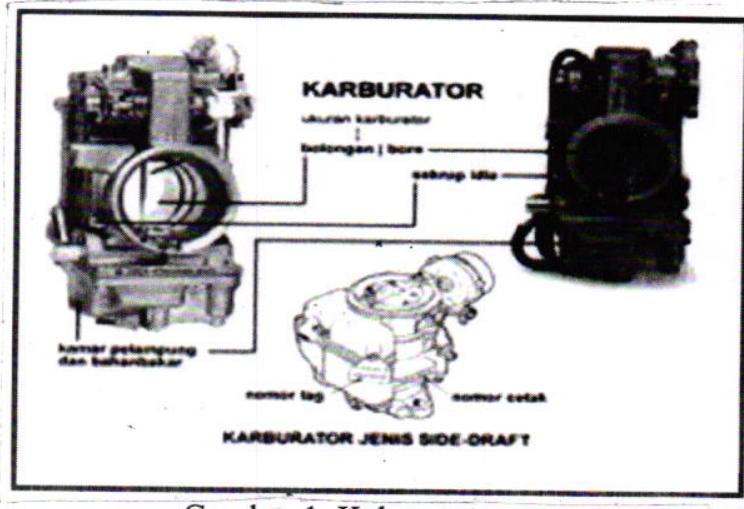

Gambar 1. Kaburator genset

Alat dan Skema instalasi Pengujian

Genset yang digunakan memiliki spesifikasi sebagai berikut :

Name : ALGEN Gasoline Genset

Generator Type : Single-phase, AC generator

Generating Capacity $\quad: 2 \mathrm{~kW}$

Voltage $: 220 \mathrm{~V}$

Frequency $\quad: 50 \mathrm{~Hz}$

Motor Type $\quad: 1$-cylinder, 4 -stroke

Engine Speed $\quad: 3000 \mathrm{rpm}$

Fuel : no-lead gasoline

Oil $\quad: S A E 15 W-40 S F$

Oil Capacity $\quad: 500 \mathrm{ml}$

Fuel Tank Capacity $\quad: 6 l$

Dimension (LxWxH) : $445 \times 385 \times 375 \mathrm{~mm}$

Net Weight

$\therefore 28 \mathrm{~kg}$

\section{Skema instalasi pengujian :}

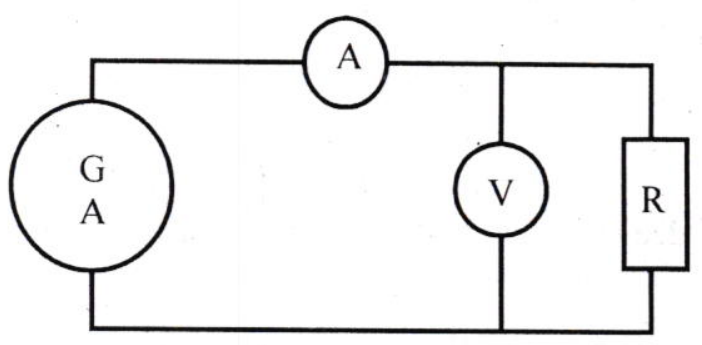

Gambar 2. Skema instalasi pengujian

Keterangan :

GAC : genset

A : meter arus

$\mathrm{V} \quad$ : meter tegangan

$\mathrm{R}$ : beban 


\section{Analisis Performansi Genset Bensin}

Performansi genset merupakan indikator nilai yang digunakan untuk mengetahui tingkat keberhasilan motor untuk melakukan konversi energi kimia bahan bakar menjadi energi mekanik. Untuk mengetahui performansi dari genset maka perlu dilakukan pengukuran terhadap parameter-parameter yang termasuk dalam performansi mesin. Beberapa parameter performansi genset adalah sebagai berikut :

\section{Daya output yang dibangkitkan}

Pada genset, daya yang berguna adalah daya listrik yang bentuk outputnya adalah daya 1 fasa yang dibangkitkan oleh generator yaitu:

$P_{\text {out }}=V_{\text {gen }} \times I_{g e n}$

Keterangan :

$\begin{array}{ll}P_{\text {out }} & =\text { Daya output genset }(\mathrm{kW}) \\ V_{\text {gen }} & =\text { Tegangan }(\mathrm{V}) \\ I_{\text {gen }} & =\text { Arus }(\mathrm{A})\end{array}$

\section{Pemakaian bahan bakar spesifik (SFC)}

Parameter ini biasa dipakai sebagai ukuran ekonomi pemakaian bahan bakar karena SFC menyatakan banyaknya bahan bakar yang terpakai per jam untuk setiap daya yang dihasilkan. Harga SFC yang lebih rendah menyatakan efisiensi yang lebih tinggi.

$\mathrm{SFC}=\mathrm{m}_{\mathrm{bb}} / \mathrm{P}_{\text {out }}(\mathrm{kg} / \mathrm{W} . \mathrm{h})$

Keterangan:

$m_{b b} \quad=$ Laju alir bahan bakar $(\mathrm{kg} / \mathrm{s})$

$E_{b b} \quad=$ Energi bahan bakar $(\mathrm{kW})$

\section{a. Efisiensi termal}

Efisiensi termal merupakan perbandingan antara daya output yang dihasilkan genset dengan daya yang dihasilkan oleh bahan bakar. Hal ini menunjukkan bahwa semakin tinggi efisiensi termal suatu genset semakin optimal kemampuan operasinya.

$\eta=P_{\text {out }} / E_{b b}(\%)$

Keterangan:

$E_{b b} \quad=$ Energi bahan bakar $(\mathrm{kW})$

$E_{b b}\left(P_{i n}\right)=m_{b b} \times L H V$

$m_{b b} \quad=$ Laju alir bahan bakar $(\mathrm{kg} / \mathrm{s})$

$L H V=$ Nilai kalor bahan bakar $(\mathrm{kJ} / \mathrm{kg})$

\section{HASIL DAN PEMBAHASAN}

\section{Komposisi Biogas}

Berdasarkan hasil pengujian komposisi biogas yang dilakukan di LABTEK X, Laboratorium Instrumentasi Departemen Teknik Kimia ITB dengan menggunakan alat Gas Chromatografi, diperoleh seperti yang ditunjukkan pada Tabel 1.

\begin{tabular}{|c|l|c|}
\hline No & \multicolumn{1}{|c|}{ Jenis G as } & Komposisi \%) \\
\hline 1 & Karbondioksida $\left(\mathrm{CO}_{2}\right)$ & 33,21 \\
\hline 2 & Nitrogen $\left(\mathrm{N}_{2}\right)$ & 27,01 \\
\hline 3 & Methan $\left(\mathrm{CH}_{4}\right)$ & 39,78 \\
\hline
\end{tabular}

Dengan menggunakan data $\mathrm{k}$

andungan metan biogas pada Tabel 1 yaitu $39,79 \%$ dan nilai kalor metan murni dari referensi yaitu $20000 \mathrm{KJ} / \mathrm{Kg}$ (Suhut, 2006) atau sama dengan $78000 \mathrm{KJ} / \mathrm{m}^{3}$, maka nilai kalor biogas $\left(\mathrm{N}_{\text {biogas }}\right)$ adalah:

$$
\begin{aligned}
& \mathrm{N}_{\text {biogas }}=\% \mathrm{CH}_{4} \times\left(\mathrm{LHV} \mathrm{CH}_{4} / \mathrm{\rho CH}_{4}\right) \\
& =39,78 \% \times\left(78000 \mathrm{KJ} / \mathrm{m}^{3} / 0,717 \mathrm{~kg} / \mathrm{m}^{3}\right) \\
& =43,477 \mathrm{MJ} / \mathrm{kg}
\end{aligned}
$$

\section{PerformansiGenset}

Dalam pengujian genset dengan bahan bakar bensin maupun biogas dilakukan dengan variasi beban yang sebanding dengan daya output dan pada putaran yang konstan pada $3000 \mathrm{rpm}$.

Hubungan Konsumsi bahan Bakar terhadap daya ouptut

Dalam pengujian genset dengan bahan bakar bensin maupun biogas dilakukan dengan variasi beban yang sebanding dengan daya output dan pada putaran yang konstan pada $3000 \mathrm{rpm}$.

Hubungan Konsumsi bahan Bakar terhadap daya ouptut

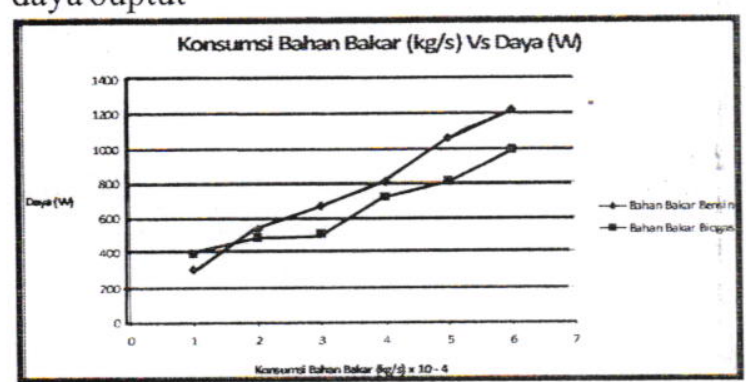

Gambar 3. Hubungan Konsumsi Bahan Bakar terhadap Daya Output 
Pada Gambar 1 terlihat bahwa dengan makin bèsar konsumsi bahan bakar baik pada genset bensin maupun pada genset biogas maka daya output juga makin besar. Hal ini menunjukkan bahwa dengan makin besarnya daya output akan membutuhkan bahan bakar yang semakin besar pula. Genset dengan bahan bakar bensin dapat mencapai daya output maksimal sebesar $1219 \mathrm{~W}$ dengan konsumsi bahan bakar 1,63 x 10 $0^{-4} \mathrm{~kg} / \mathrm{s}$, sedangkan genset dengan bahan bakar biogas hanya dapat mencapai daya output maksimal $989 \mathrm{~W}$ dengan konsumsi bahan bakar yaitu 2,95 $\times 10^{-4} \mathrm{~kg} / \mathrm{s}$. Berdasarkan data diatas maka untuk menghasilkan daya output genset yang sama sebesar $1000 \mathrm{~W}$ atau $1 \mathrm{~kW}$ diperlukan $1,34 \times 10^{-4}$ $\mathrm{kg} / \mathrm{s}$ bahan bakar bensin sedangkan dengan biogas diperlukan sebesar $2,98 \times 10^{-4} \mathrm{~kg} / \mathrm{s}$. Dengan demikian, genset tersebut lebih boros bila menggunakan bahan bakar biogas dibandingan dengan menggunakan bahan bakar bensin. Hal ini kemungkinan disebabkan oleh kondisi genset biogas yang belum optimal mengingat genset tersebut adalah hasil modifikasi yang masih memerlukan perbaikanperbaikan, ataupun juga kemungkinan karena komposisi metan dalam biogas yang kecil (kurang maksimal).

\section{Hubungan daya output terhadap efisiensi}

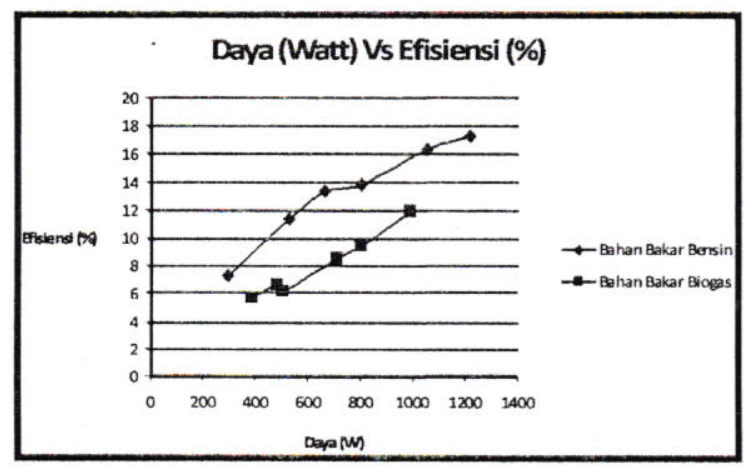

Gambar 4. Hubungan Daya Output terhadap Efisiensi

Pada Gambar 2 terlihat bahwa baik pada genset berbahan bakar bensin maupun pada genset berbahan bakar biogas, makin besar daya output maka efisiensi juga makin besar. Hal tersebut menunjukkan bahwa efisiensi berbanding lurus dengan daya output. Untuk genset berbahan bakar bensin dicapai efisiensi tertinggi sebesar $17,24 \%$ pada daya output sebesar 1219 watt, sedangkan pada genset berbahan bakar biogas hanya mencapai efisiensi sebesar $11,9 \%$ pada daya output 989 watt.

\section{Hubungan daya output terhadap SFC}

SFC atau Specific Fuel Consumption adalah suatu parameter yang menunjukan ukuran ekonomi pemakaian bahan bakar karena SFC menyatakan banyaknya bahan bakar yang terpakai per jam untuk setiap daya output yang dihasilkan. Harga SFC yang rendah menunjukan efisiensi yang lebih tinggi.

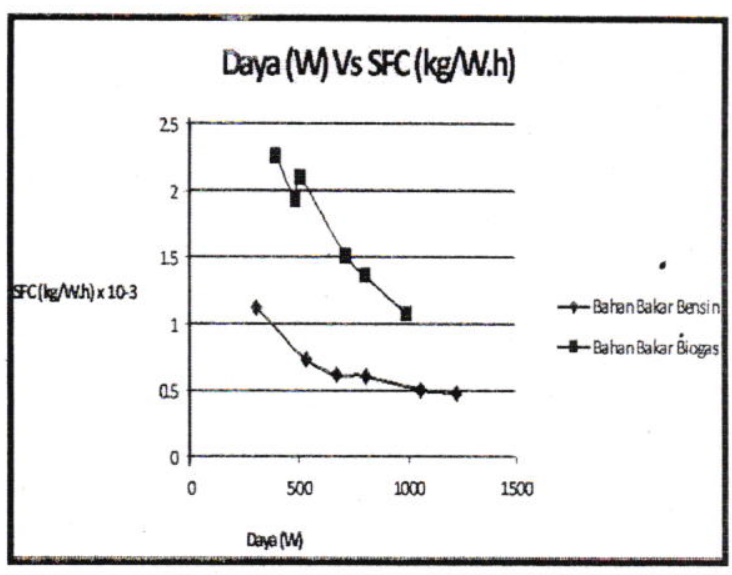

Gambar 5. Hubungan Daya Output terhadap SFC

Pada Gambar 3 terlihat bahwa SFC genset berbahan bakar bensin cenderung berada di bawah bahan bakar biogas. Hal ini menunjukkan bahwa genset berbahan bakar bensin lebih hemat dibandingkan dengan genset berbahan bakar biogas. SFC terkecil untuk genset bensin adalah sebesar $0,48 \times 10^{-3} \mathrm{Kg} / \mathrm{Wh}$ yang dicapai pada daya output terbesar yaitu 1219 watt, sedangkan SFC terkecil untuk genset biogas adalah sebesar $1,07 \times 10^{-3} \mathrm{~kg} / \mathrm{W}$.h yang dicapai pada daya output sebesar 989 watt.

\section{KESIMPULAN}

Genset dengan bahan bakar biogas dapat mencapai daya output maksimal $989 \mathrm{~W}$ pada konsumsi bahan bakar yaitu $2,95 \times 10^{-4} \mathrm{~kg} / \mathrm{s}$, sedangkan genset dengan bahan bakar biogas hanya dapat mencapai daya output sebesar 1219 W pada konsumsi bahan bakar 1,63 x $10^{-4} \mathrm{~kg} / \mathrm{s}$. Dengan demikian, untuk menghasilkan daya output sebesar $1000 \mathrm{~W}$ atau $1 \mathrm{~kW}$ diperlukan $1,34 \times 10^{-4} \mathrm{~kg} / \mathrm{s}$ bahan bakar bensin sedangkan dengan bahan bakar biogas diperlukan konsumsi bahan bakar sebesar $2,98 \times 10^{4} \mathrm{~kg} / \mathrm{s}$. 
Pada genset berbahan bakar biogas hanya mencapai efisiensi sebesar 11,9\% dengan SFC sebesar $0,48 \times 10^{-3} \mathrm{Kg} /$ W.h pada daya output 989 watt, sedangkan pada genset berbahan bakar bensin mencapai efisiensi tertinggi sebesar $17,24 \%$ dengan SFC sebesar $1,07 \times 10^{-3} \mathrm{~kg} / \mathrm{W} . \mathrm{h}$ pada daya output sebesar 1219 watt. Hal ini menunjukkan bahwa genset berbahan bakar biogas masih lebih boros dibandingkan dengan genset bensin.

\section{DAFTAR PUSTAKA}

1. Arismunandar, Wiranto. 1996. Motor Bakar Torak. Bandung: ITB.

2. Daryanto. 2003. Motor Bensin pada Mobil. Bandung: Yrama Widya.

3. Marapung, Muslimin. 1979. Teknik Tenaga Listrik. Bandung: Armico.

4. Morris, Noel. 1987. Dasar-dasar Listrik dan Elektronika. Jakarta: Gramedia.

5. Pudjanarsa, Astu. 2006. Mesin Konversi Energi. Surabaya: Andi.

6. Saragih, Roni Hotmartuah. 2009. Studi Eksperimental Performansi Motor Otto Berbahan Bakar Campuran Premium Dengan Zat Aditif Berbentuk Cair. Departemen Teknik Mesin Universitas Sumatera Utara: Medan

7. Simamora, Suhut. 2005. Membuat Biogas Pengganti Bahan Bakar Minyak dan Gas dari Kotoran Ternak. Jakarta: Agromedia Pustaka.

8. Wijaya, Mochtar. 2000. Dasar-dasar Mesin Listrik. Jakarta: Djambatan 